\title{
A large-eddy simulation of the phase transition of ammonium nitrate in a convective boundary layer
}

\author{
J. M. J. Aan de Brugh, ${ }^{1,2,5}$ H. G. Ouwersloot, ${ }^{1,3}$ J. Vilà-Guerau de Arellano, ${ }^{1}$ and \\ M. C. $\mathrm{Krol}^{1,4}$ \\ Received 3 August 2012; revised 22 December 2012; accepted 3 January 2013; published 30 January 2013.
}

[1] Under warm and dry conditions, ammonium nitrate aerosol outgasses to form ammonia and nitric acid in the lower atmospheric boundary layer. In the upper boundary layer, where the temperature is lower and the relative humidity is higher, nitric acid and ammonia condense back to the aerosol phase. Measurements show that aerosol nitrate mixing ratios increase with altitude, confirming this phase transition. Since phase equilibrium is not reached instantaneously, updrafts transport aerosol-poor air from the surface to high altitudes and aerosol-rich air subsides from high altitudes to the surface under turbulent conditions. As a result, the partitioning deviates fiom equilibrium, so the horizontal and temporal variabilities of the aerosol nitrate mixing ratio are enhanced and a continuous downward aerosol nitrate flux emerges. We postulate that observations of this variability and flux should not be interpreted as instrument noise and deposition of nitrate. In an idealized large-eddy simulation (LES) experiment of a convective boundary layer, we find that the larger variability and flux occurred at about one third of the boundary layer height. Both are largest when the gas-aerosol partitioning time scale is assumed to be about half the time scale of turbulence. Our LES result shows negatively skewed nitrate mixing ratios. Under colder conditions, a smaller fraction of ammonium nitrate aerosol outgasses at the surface, so the absolute effect of nitrate repartitioning becomes smaller. However, dimensionless statistical properties do not change as long as the turbulent properties of the boundary layer remain similar. This indicates that the identified processes are also present under colder conditions.

Citation: Aan de Brugh, J. M. J., H. G. Ouwersloot, J. Vilà-Guerau de Arellano, and M. C. Krol (2013), A large-eddy simulation of the phase transition of ammonium nitrate in a convective boundary layer, J. Geophys. Res. Atmos., 118, 826-836, doi:10.1002/jgrd.50161.

\section{Introduction}

[2] Aerosols have a pronounced influence on the climate system, both directly by scattering and absorbing incoming solar radiation [Hess et al., 1998; Haywood and Boucher, 2000; Solomon et al., 2007; Intergovernmental Panel on Climate Change, 2007] and indirectly by altering cloud properties [Rosenfeld et al., 2008; Kaufman et al., 2002]. Knowledge about the combined climate effect of aerosols is poor compared to that of the climate effect of greenhouse gases. In the Netherlands, nearly half (42-48\%) of the fine aerosol $\left(\mathrm{PM}_{2.5}\right)$ mass consists of secondary inorganic aerosols (ammonium nitrate and ammonium sulfate) [Weijers et al., 2011],

\footnotetext{
${ }^{1}$ Department of Meteorology and Air Quality, Wageningen University, Wageningen, The Netherlands.

${ }^{2}$ TNO, Earth, Environment and Life Sciences, Research Group Clinate, Air and Sustainability, Utrecht, The Netherlands.

${ }^{3}$ Max Planck Institute for Chemistry, Mainz, Germany.

${ }^{4}$ Institute for Marine and Atmospheric Research, Utrecht, The Netherlands.

${ }^{5}$ Now at: Netherlands Institute of Space Research, Utrecht, The Netherlands.

Corresponding author: J. M. J. Aan de Brugh, Department of Meteorology and Air Quality, Wageningen University, Bldg. 100, 6708 PB, Wageningen, The Netherlands. (joost.aandebrugh(@wur.nl)

(C2013. Anterican Geophysical Union. All Rights Reserved. 2169-897X/13/10.1002/jgrd.50161
}

which are the dominant anthropogenic aerosol species in the size range of maximum light scattering $(0.4-1.0 \mu \mathrm{m})$ [ten Brink et al., 1997]. Furthermore, secondary inorganic aerosols are effective cloud condensation nuclei, because of their size and water solubility. During the last 25 years, nitrogen oxide emissions have been reduced to a smaller extent than sulfur dioxide emissions [Vestreng et al., 2007, 2009]. Ammonia emissions in the Netherlands are very ligh due to intensive livestock [Buijsman et al., 1987]. This emission stoichiometry implies that ammonium nitrate aerosol is particularly important in the Netherlands.

[3] Under warm and dry conditions, ammonium nitrate aerosol dissociates and outgasses to form ammonia and nitric acid gas [Stelson and Seinfeld, 1982]. As the temperature is highest at low altitudes, ammonium nitrate will outgas near the surface and condense back onto aerosols in the upper boundary layer. In a convective boundary layer, ammonium nitrate is being mixed continuously between low and high altitudes, where different phases prevail. In theory, this interaction between turbulence and gas-aerosol partitioning induces spatial variability on the aerosol nitrate mixing ratio field. Here, we use a large-eddy simulation (LES) to study the main controlling processes driving this variability and to quantify the vertical profiles of the aerosol nitrate mixing ratio, flux, variance, and skewness. 
[4] Large-eddy simulations have been used to investigate the effect of small-scale turbulence on processes such as chemical reactions. For instance, Ouwersloot et al. [2011] studied the effect of mesoscale circulations, induced by surface heterogeneity, on the reaction between isoprene and the hydroxyl radical. The advantage of large-eddy simulations is that the segregation of chemical species is explicitly resolved [Ouwersloot et al., 2011]. Segregation between the hydroxyl radical and volatile organic compounds has also been investigated without LES [Dlugi et al., 2010; Pugh et al., 2011]. Krol et al. [2000] studied the effect of heterogeneous emissions of hydrocarbons on their oxidation rates. For both the studies of Ouversloot et al. [2011] and Krol et al. [2000], the chemical reaction is slowed down because the concentrations of the reacting chenicals anticorrelate in space. This segregation has been studied in idealized cases by Schumann [1989], Sykes et al. [1992], and Vilà-Guerau de Arellano et al. [1993b]. LES studies have also been performed on physical processes such as cloud formation [van Heerwaarden and Vilà-Guerau de Arellano, 2008]. Like partitioning of ammonium nitrate, cloud formation is a reversible phase transition induced by temperature and moisture.

[5] Wolff et al. [2010] pointed out that the phase transition of nitrate may induce a flux divergence. Without correcting for these effects, dry deposition of aerosol nitrate may be substantially overestimated. For nitric acid, these fluxes are reversed and could falsely be interpreted as emission of nitric acid [Huebert et al., 1988; Neftel et al., 1996; Nemitz et al., 2004a; Zhange et al., 1995]. Phase transitions and chemical reactions at time scales comparable to that of turbulence make the flux-gradient relationship more complex as demonstrated by Vilà-Guerau de Arellano et al. [1993a]. The time scale of turbulence is the typical time for air parcels within the boundary layer to be transported and mixed and has typical values of 15-20 min during daytime. The time scale of gas-aerosol partitioning is the characteristic time in which the gas-aerosol system restores to equilibrium. Theoretical studies pointed out that the time scale of partitioning depends strongly on the aerosol size and composition [Meng and Seinfeld, 1996; Wexler and Seinfeld, 1992; Shiraiwa et al., 2011]. Fine liquid aerosols equilibrate well within one eddy-turnover time (15-20 min), while coarse solid aerosol equilibrates much slower. Several experimental studies investigated whether or not a gas-aerosol system remains in equilibrium, which is related to the ratio between the time scales of partitioning and turbulence. Whereas several studies [Zhang et al., 2003; Takahama et al., 2004; Yu et al., 2005] conclude that the equilibrium corresponds well to the observations, other studies [Moya et al., 2001; Fisseha et al., 2006; Morino et al., 2006; Schaap et al., 2011] show that during summer and daytime, observations show a larger particulate phase than the equilibrium, which can be explained by a non-instantaneous equilibrium.

[6] Partitioning of ammonium nitrate in the convective boundary layer has been investigated in a study with airborne measurements [Morgan et al., 2010]. They observed increasing aerosol nitrate mixing ratio with altitude throughout the entire boundary layer on 8 May 2008 in the Netherlands. In contrast, observations on 21 May showed no further increase in the nitrate mixing ratio from $500 \mathrm{~m}$ altitude onward (not shown in Morgan et al. [2010]). Interestingly, the horizontal variability of nitrate mixing ratios at any altitude was much greater on 8 May than on 21 May. None of these features were present in the observations of sulfate, which is not subject to phase transition. Inspired by these observations, Aan de Bnigh et al. [2012] performed a one-dimensional model study on the partitioning of ammonium nitrate with a single-column model. They discussed how delayed gas-aerosol equilibrium in the model can improve the match between the model and the observations. Regarding the results from experimental and theoretical studies, it seems likely that a gas-aerosol partitioning time scale close to the turbulent time scale is representative for a clear day in May at Cabauw.

[7] Phase transition of ammonium nitrate has been investigated in many other model studies as well, for instance by Brost et al. [1998], Kramm and Dlugi [1994], Nemitz and Sutton [2004], Ryder [2010], and van Oss et al. [1998]. However, none of these studies used large-eddy simulations. Our large-eddy simulation complements these studies by adding an explicit representation of the segregations of concentrations of different species, temperature, and humidity. Moreover, our simulation focuses on the middle boundary layer (around $500 \mathrm{~m}$ altitude) rather than the surface layer. In contrast to the abovementioned studies, surface-layer processes, such as dry deposition, will not be analyzed in this paper. The goal of this paper is to unravel the interaction between boundarylayer turbulence and gas-aerosol partitioning of nitrate. To maintain focus on this interaction, other processes have not been included in the model. Our specific research questions are:

1. What features (e.g. variability and flux) of aerosol nitrate are explicitly reproduced in an LES of an ammoniumnitrate-sulfate system under diurnal convective conditions?

2. What is the dependence of these features on the assumed time scale of gas-aerosol partitioning and on temperature?

[8] Additionally, we discuss what observational evidence could be obtained to acquire information about gas-aerosol partitioning.

\section{Numerical Simulation}

[9] Our simulation of the ammonium-nitrate-sulfate system will focus on the daytime situation for two reasons: First, turbulent mixing, which is active during daytime, is the main driver in transport and mixing. Secondly, the radiative impact of aerosols is relevant during daytime. All the numerical experiments start at 7:00 UTC and we obtain model output every minute between 13:00 and 16:00 UTC, referred to as the analysis period. We will analyze the phase state of the semi-volatile aerosols and use the aerosol nitrate mixing ratio as indicator. Throughout this paper, when nitrate is mentioned, it refers to just the nitrate in the aerosol phase $\left(\mathrm{NO}_{3}^{-}\right)$unless "total nitrate" $\left(\mathrm{NO}_{3}^{-}+\mathrm{HNO}_{3}\right)$ is explicitly mentioned.

[10] We use the Dutch Atmospheric Large-Eddy Simulation (DALES) [Heus et al., 2010], version 3.2. This model originates from Nieuwstadt and Brost [1986] and has been further developed and improved [Cuijpers and Duynkerke, 1993; Dosio, 2005]. DALES explicitly resolves processes on a relatively large scale using the filtered Navier-Stokes equations in combination with the Boussinesq approximation [Heus et al., 2010]. In general, the filter size is set equal to the grid size of the simulations. Subfilter-scale processes are parameterized using one-and-a-half-order closure. 
Table 1. Uniformly Initialized Mixing Ratios in This Study

\begin{tabular}{lc}
\hline Species & Mixing Ratio $(\mathrm{ppb})$ \\
\hline Total ammonium & 23.0 \\
Total nitrate & 3.6 \\
Total sulfate & 1.3 \\
\hline
\end{tabular}

[11] The vertical grid is a non-equidistant grid of 200 cells from the surface up to about $3 \mathrm{~km}$, with a fine resolution close to the surface and a coarser resolution aloft. This grid approximates pressure levels with $150 \mathrm{~Pa}$ per cell, which is inspired by the column model study of Aan de Brugh et al. [2012]. In our cases, the boundary layer does not grow larger than $2 \mathrm{~km}$, which implies that the vertical domain size is sufficiently large for a boundary-layer study. The horizontal grid consists of $64 \times 64$ cells of $50 \times 50 \mathrm{~m}$ each leading to a simulation of a domain of $3200 \times 3200 \mathrm{~m}$. As usual, periodic boundary conditions are employed to mimic an infinite homogeneous convective boundary layer [Heus et al., 2010]. The maximum time step is $1 \mathrm{~s}$. Non-resolved fluxes, which are negligible except at the surface, are parameterized.

[12] The DALES is extended with a chemistry module, allowing for simultaneous simulation of both boundary-layer dynamics and chemistry [Vilà-Guerau de Arellano et al., 2005]. Our chemistry scheme only involves gas-aerosol partitioning of ammonium nitrate, using six scalars for the mixing ratios of the aerosol species: sulfate $\left(\mathrm{SO}_{4}^{2-}\right)$, bisulfate $\left(\mathrm{HSO}_{4}^{-}\right)$, nitrate $\left(\mathrm{NO}_{3}^{-}\right)$, ammonium $\left(\mathrm{NH}_{4}^{+}\right)$, and the gas species: nitric acid $\left(\mathrm{HNO}_{3}\right)$ and ammonia $\left(\mathrm{NH}_{3}\right)$. The equilibrium between the gas and the aerosol phase is calculated with ISORROPIA version 2 [Fountoukis and Nenes, 2007], an extension of the original version as described in Nenes et al. [1998]. This cquilibrium depends on the absolute temperature and the relative humidity. We apply the tendency by first-order nudging:

$$
\frac{\mathrm{dC}}{d t}=\frac{\mathrm{C}_{\mathrm{eq}}-\mathrm{C}}{\tau_{p}}
$$

[13] Here, $\mathbf{d C} / d t$, is the tendency of the mixing ratios, $\mathbf{C}_{\mathbf{e q}}$ are the equilibrium mixing ratios calculated by ISORROPIA, $\mathrm{C}$ are the actual mixing ratios, and $\tau_{p}$ is the partitioning time scale.

[14] Because chemical processes of aerosols are limited by bulk diffusion [Shiraiwa et al., 2011], the time scale of gasaerosol partitioning depends strongly on microphysical properties of the acrosols such as size and viscosity. Because these microphysical acrosol properties have not been measured during IMPACT, there is a large uncertainty around the $\tau_{p}$ value. The ratio between $\tau_{p}$ and the time scale of turbulence $\left(\tau_{t}\right)$ is particularly important in this study, because partitioning and turbulent mixing are the two processes that are modeled explicitly. The time scale of turbulence is obtained from the DALES results as

$$
\tau_{t} \equiv \frac{z_{i}}{w_{*}}
$$

where $\tau_{i}$ is the time scale of turbulence, $w_{* k}$ is the convective velocity scale, and $z_{i}$ is the boundary layer height.

[15] We perform simulations in which we vary $\tau_{p}$. We present the results with $\tau_{p}=1800 \mathrm{~s}$ as the main results and show how the results change with a different partitioning time scale. Note that $1800 \mathrm{~s}$ is close to typical time scales of turbulent mixing in a convective boundary layer and that therefore the interaction between mixing and gas-aerosol partitioning is explicitly simulated.

[16] This research employs an idealized model setup, in which just the interaction between turbulence and gas-aerosol partitioning is simulated. To mimic typical fair-weather conditions, we imitate the meteorological conditions of 8 May 2008 at Cabauw, a clear day during the IMPACT campaign. This is done by setting initial conditions and boundary conditions such that the temperature and relative humidity at the surface correspond well to the observations at Cabauw. To acquire satisfactory meteorological boundary conditions, the meteorological situation has been simulated with the Wageningen University single Column Model (WUSCM) [Aan de Brugh et al., 2012]. Thereby, we checked with which boundary conditions the results of WUSCM correspond well to observations from the CESAR website (http://www cesar-observatory. n] [Russchenberg et al., 2005]). These boundary conditions were adopted for the LES.

[17] The mixing ratios of total sulfate $\left(\mathrm{SO}_{4}^{--}+\mathrm{HSO}_{4}^{-}\right)$, total nitrate $\left(\mathrm{HNO}_{3}+\mathrm{NO}_{3}^{-}\right)$, and total ammonium $\left(\mathrm{NH}_{3}+\mathrm{NH}_{4}^{+}\right)$ are initialized uniformly over the entire domain (including the fire troposphere) to mixing ratios that are observed with

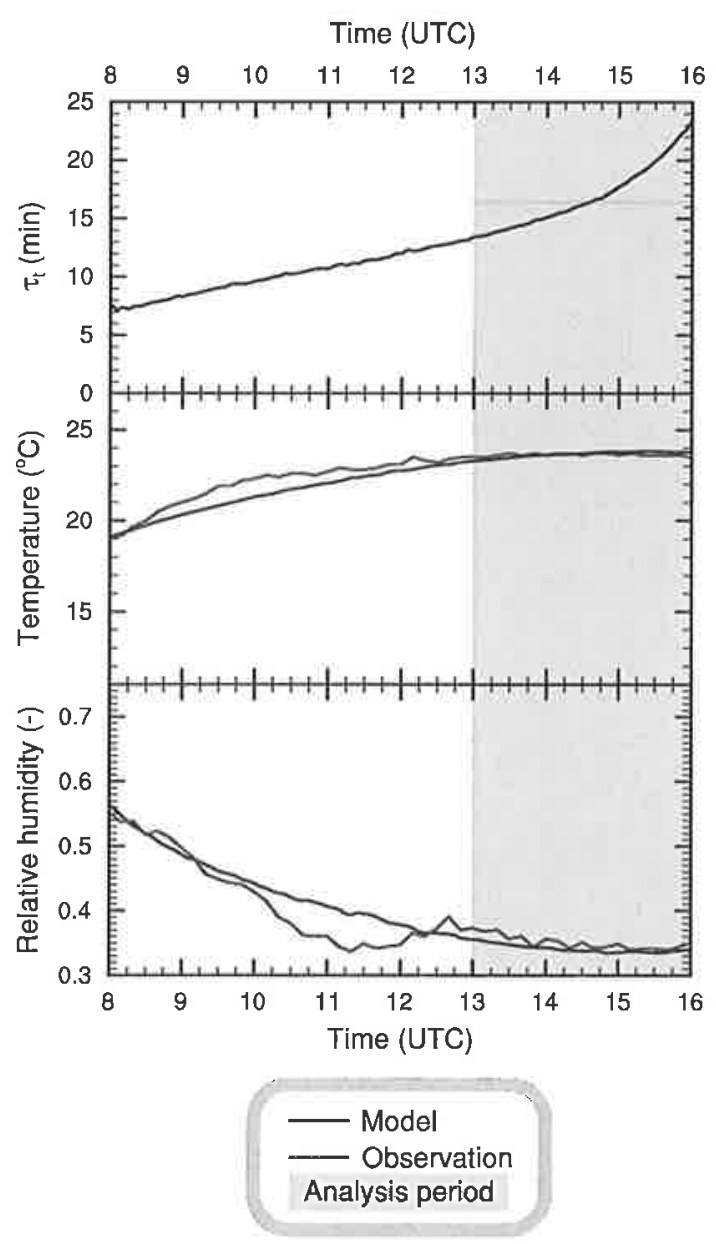

Figure 1. Modeled and obscrved surface temperature and relative humidity, and modeled time scale of turbulence $\left(\tau_{t}\right)$ at Cabauw on 8 May 2008. The analysis period is shaded. 
the MARGA instrument [Thomas et al., 2009; ten Brink et al., 2009] at Cabauw on 8 May 2008 at the time of the flight mission on that day. These mixing ratios are $1.3 \mathrm{ppb}$ total sulfate, $3.6 \mathrm{ppb}$ total nitrate, and $23 \mathrm{ppb}$ total ammonium (Table 1). Note that ammonia is sufficiently abundant to neutralize both sulfuric and nitric acid, a situation typical for the Netherlands. Exchange processes at the surface are not imposed. By doing so, this model setup allows us to avoid complex boundary conditions and to simulate a homogeneous convective boundary layer close to the observed situation on 8 May shown in Morgan et al. [2010].

\section{Results}

[18] We first highlight the meteorological conditions of our main simulation: 8 May 2008. Then, we analyze the interaction between turbulence and nitrate repartitioning assuming a time scale of partitioning equal to $1800 \mathrm{~s}$. Subsequently, we analyze how the interaction between turbulence and repartitioning changes with different partitioning time scales. Finally, we investigate the sensitivity to colder conditions.

[19] Figure 1 shows the modeled and observed temperature and relative humidity at the surface, and the modeled time scale of turbulence, starting at 8:00 UTC. As stated in section 2, the initial conditions and boundary conditions are set such that the observations are reproduced. Both the modeled temperature and relative humidity at the surface remain very close to the observations, especially during the analysis period (13:00-16:00 UTC), with root mean square errors of $0.16^{\circ} \mathrm{C}$ for the temperature and $1.1 \%$ for the relative humidity. Moreover, with standard deviations of $0.16^{\circ} \mathrm{C}$ for the modeled temperature and $0.6 \%$ for the modeled relative humidity during the analysis period, it can be stated that the meteorological conditions remain relatively constant during these $3 \mathrm{~h}$, so the diumal evolution plays only a minor role. During the analysis period, the time scale of turbulence (equation (2)) reaches typical values of 15 to $20 \mathrm{~min}$. The boundary layer grows to about $1900 \mathrm{~m}$ in the afternoon.

[20] To show the 2D vertical structure, we present snapshots of potential temperature, specific humidity, actual nitrate mixing ratio, and nitrate equilibrium at 14:30 UTC (middle of analysis period) in Figure 2. In all four panels, the wind is shown as vector field. Close to the surface, updrafts are characterized by higher potential temperatures and higher specific humidities that indicate the transport of heat and moisture from the surface into the atmospheric boundary layer. In the
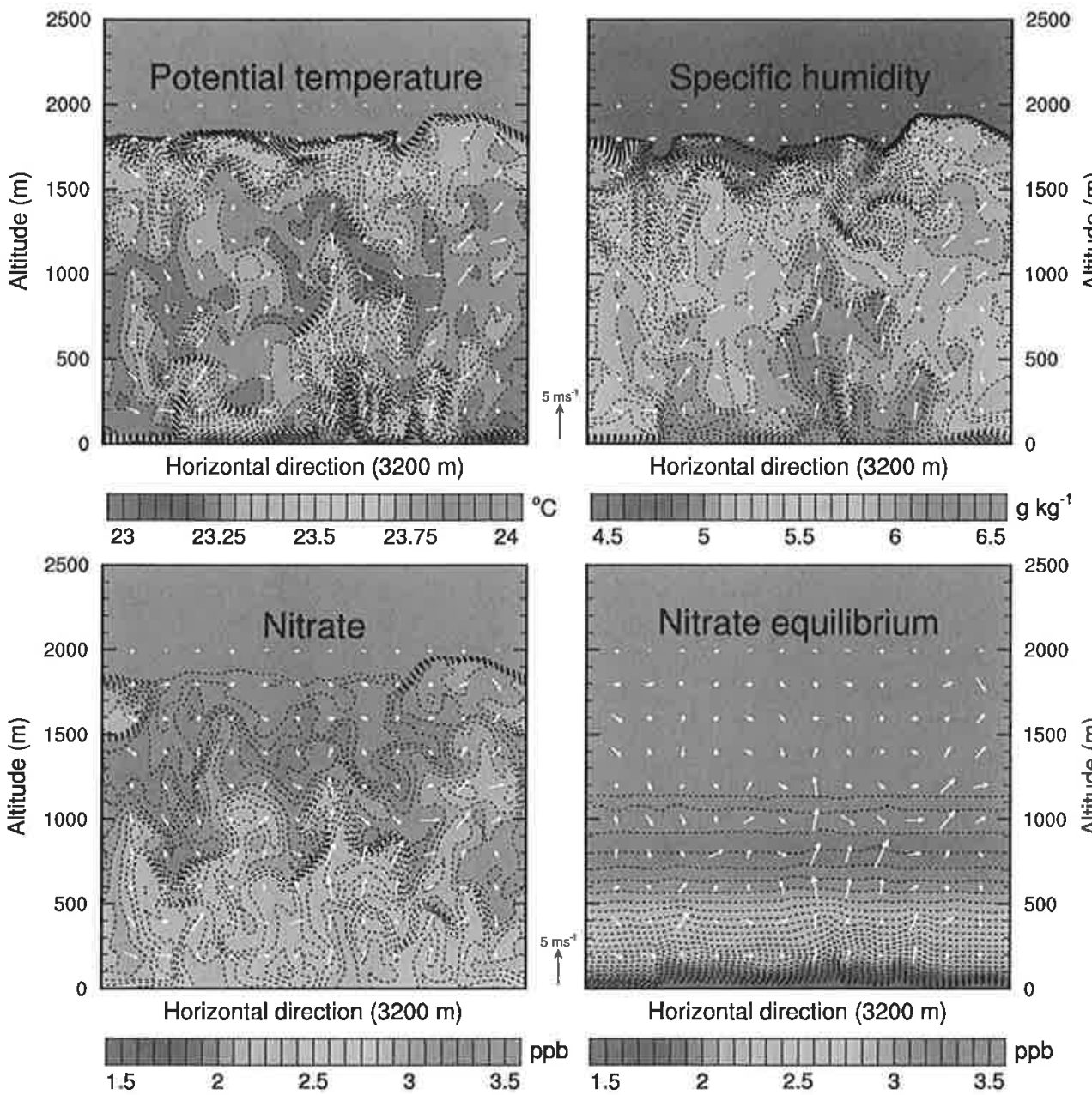

Horizontal direction (3200 m)
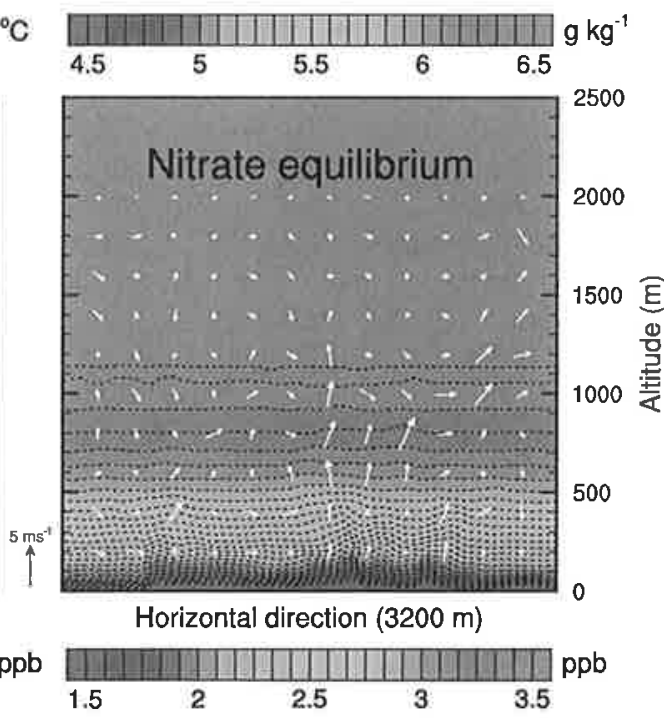

Figure 2. Vertical 2D snapshots on 14:30 UTC of modeled potential temperature, specific humidity, actual nitrate mixing ratio and equilibrium nitrate mixing ratio, along with a vector field for the wind in the two displayed directions. The time scale of partitioning is set to $1800 \mathrm{~s}$. 
upper boundary layer; warmer and drier air is transported by the subsidence motions because of entrainment. The nitrate equilibrium (bottom of right column) depends strongly on the altitude due to decreasing absolute temperature and increasing relative humidity at higher altitudes. The horizontal variability in the nitrate equilibrium due to horizontal variability of potential temperature and specific humidity is small ( $\sigma<0.1 \mathrm{ppb}$ at surface, decreasing rapidly with altitude).

[21] Due to the assumed non-instantaneous equilibrium $\left(\tau_{p}=1800 \mathrm{~s}\right)$, the actual nitrate mixing ratio differs substantially from the equilibrium. At the surface, the average mixing ratio of nitrate $(2.6 \mathrm{ppb} ; 72 \%$ of total nitrate) is significantly higher than the equilibrium (1.4ppb; $39 \%$ of total nitrate) due to mixing of aerosol-rich air from higher altitudes. At higher altitudes, the reverse is the case. From $1200 \mathrm{~m}$ onward, the equilibrium is shifted virtually completely $(>98 \%)$ toward the aerosol phase. The actual nitrate mixing ratio, on the other hand, is only $3.1 \mathrm{ppb}(86 \%$ of total nitrate) at $1200 \mathrm{~m}$. Only in the free troposphere, where the influence of mixing is small, the simulated nitrate mixing ratio equals the equilibrium mixing ratio. The simulated nitrate mixing ratio displays more horizontal variability than the equilibrium, because updrafts transport aerosol-poor air and downdrafts transport aerosol-rich air.

[22] Variability in the nitrate mixing ratio is also visible in the temporal domain even though there is no significant temporal evolution in the meteorological conditions during the analysis period (see Figure 1). Figure 3 shows viltual measurements of the nitrate mixing ratio and the vertical wind in a stationary virtual balloon at 100,500 , and $1300 \mathrm{~m}$ altitude. On any altitude, the simulated nitrate mixing ratio and the vertical wind show rapid oscillations. Striking is the strong anticorrelation between nitrate and vertical wind, especially at $500 \mathrm{~m}$ altitude $(r=-0.53$ at $100 \mathrm{~m}, r=-0.78$ at $500 \mathrm{~m}$, and $r=-0.68$ at $1300 \mathrm{~m}$ ). Except for the lowest altitude, which is located in the surface layer, specific updrafts can be identified around 13:45 UTC and 15:00 UTC, in which the nitrate mixing ratio is significantly (up to $0.5 \mathrm{ppb}$ ) lower.

\subsection{Vertical Profiles}

[23] The vertical nitrate flux is one of the main contributions in the $1 \mathrm{D}$ budget equation of the horizontally averaged nitrate mixing ratio. In order to analyze it, we first introduce the 1D budget equation for the potential temperature [Stull, 1988]:

$$
\frac{\partial \bar{\theta}}{\partial t}=\frac{-\overline{\partial w^{\prime} \theta^{\prime}}}{\partial z}
$$

[24] Here, $\overline{w^{\prime} \theta^{\prime}}$ is the potential-temperature flux. Except for the surface, there is no additional production or loss term, so the potential temperature is inert. If we differentiate equation (3) with respect to $z$, we obtain

$$
\frac{\partial^{2} \bar{\theta}}{\partial t \partial z}=-\frac{\partial^{2} w^{\prime} \theta^{\prime}}{\partial z^{2}}
$$

[25] In the quasi steady state approximation, the change of the potential-temperature gradient in time (left-hand side of equation (4)) approximates zero due to intense mixing

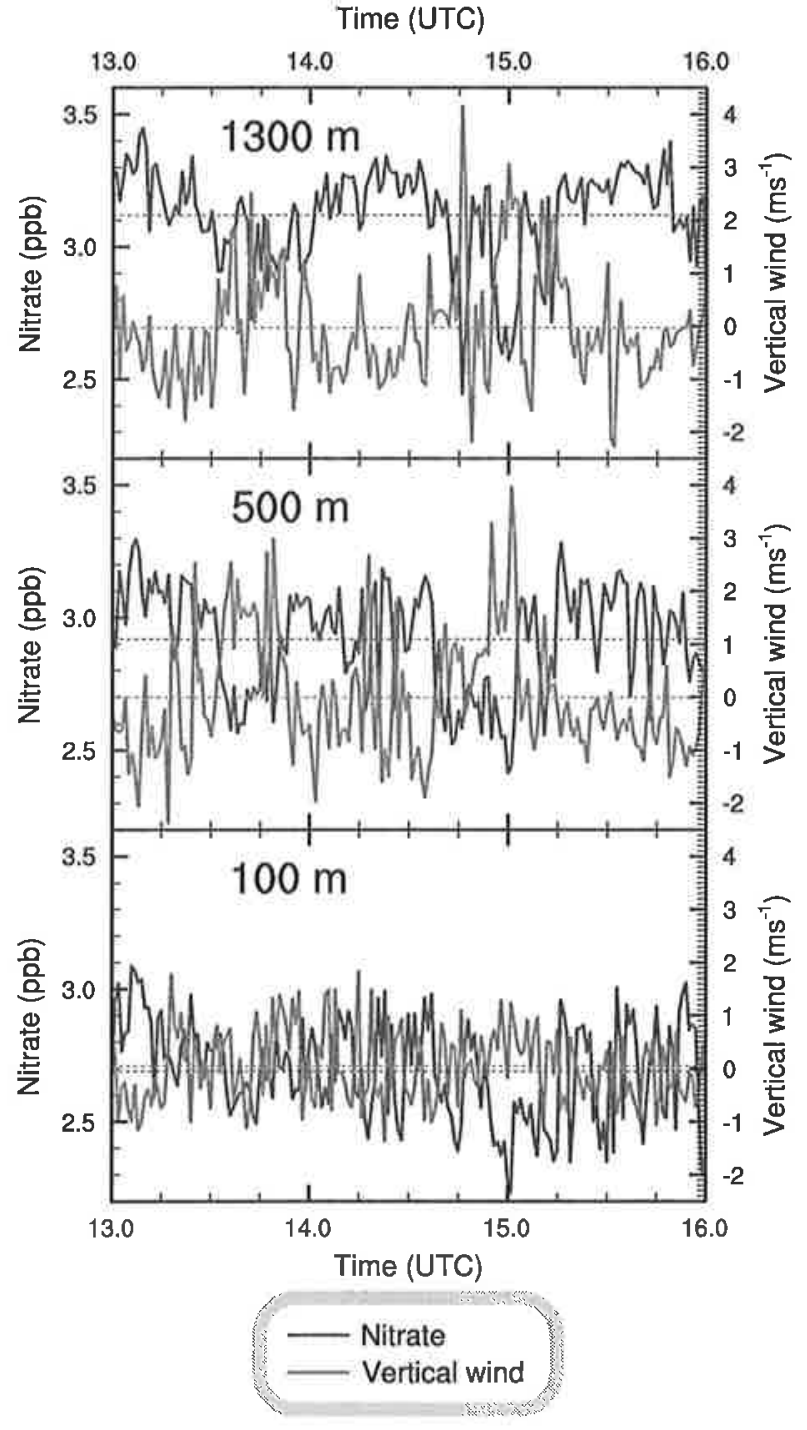

Figure 3. Modeled nitrate mixing ratio and vertical wind at a fixed point at three different altitudes. The time-averaged values are marked with dotted lines. The time scale of partitioning is set to $1800 \mathrm{~s}$.

of the convective boundary layer. This means that the riglithand side approximates zero as well. Therefore, the flux varies linearly with altitude as derived in the mixed-layer approach by Tennekes and Driedonks [1981, see for instance Figure 1 therein].

[26] For chemical tracers with a production or loss term throughout the boundary layer, like for nitrate, a chemical term enters the 1D budget equation:

$$
\begin{gathered}
\frac{\partial \bar{C}}{\partial t}=-\frac{\overline{\partial w^{\prime} C^{\prime}}}{\partial z}+f \\
\frac{\partial^{2} \bar{C}}{\partial t \partial z}=-\frac{\partial^{2} w^{\prime} C^{\prime}}{\partial z^{2}}+\frac{\partial f}{\partial z}
\end{gathered}
$$

[27] Here, $C$ is the mixing ratio of the chemical and $f$ is a production (or loss) function. Nitrate outgasses at low altitudes and nitric acid condenses onto aerosols at high 
altitudes. Consequently, nitrate has a sink (negative $f$ ) close to the surface and a source (positive $f$ ) aloft. This implies that $\partial f l \partial z$ is positive for the majority of the boundary layer: We apply the quasi steady state approximation to equation (6) as well, so the left-hand side approximates zero. To satisfy the equation, the second derivative of the nitrate flux must be a positive number. Therefore, we expect a convex flux profile for nitrate rather than a linear one.

[28] Figure 4 shows the modeled vertical profiles of five statistical quantities. As predicted, the flux profile (top of left column) is convex with a maximum downward flux of -0.21 ppb ms ${ }^{-1}$ at about $600 \mathrm{~m}$ altitude and it approaches zero at the surface and at the top of the boundary layer. The correlation coefficient between nitrate mixing ratio and vertical wind reaches its maximum negative value of -0.82 also at about $600 \mathrm{~m}$ altitude, although this value stays relatively constant between 400 and $900 \mathrm{~m}$ altitude. This means that for these altitudes and an assumed partitioning time scale of $1800 \mathrm{~s}$, updrafts can reliably be associated with lower nitrate mixing ratios. Worth noting is that the correlation coefficient between the nitrate mixing ratio and the specific humidity (not shown) is around -0.8 throughout the entire boundary layer, indicating that the current specific humidity is an even better indicator of an air parcel's half-hour history than the current vertical wind. However, whether the specific humidity or the vertical wind is more strongly anticorrelated with the nitrate mixing ratio highly depends on the assumed partitioning time scale.

[29] The flux is related to the correlation coefficient with the following formula:

$$
r_{w^{\prime} C} \equiv \frac{\overline{w^{\prime} C^{\prime}}}{\sigma_{w} \sigma_{C}}
$$

[30] Here, $w^{\prime} C^{\prime}$ is the nitrate flux, $r_{w C}$ is the correlation coefficient between nitrate mixing ratio and vertical wind, $\sigma_{C}$ is the standard deviation of the nitrate mixing ratio, and $\sigma_{w}$ is the standard deviation of the vertical wind. The standard deviation of the nitrate mixing ratio (top of right column of Figure 4) peaks at a lower altitude than that of vertical wind, although both depend on turbulence. At lower altitudes, the gradient in the nitrate mixing ratio is stronger, so turbulence enhances $\sigma_{C}$ to a greater extent than at higher altitudes. The additional peak in the nitrate standard deviation at $1800 \mathrm{~m}$ is caused by entrainment of air from the free troposphere of which the nitrate is completely $(>99 \%)$ in the aerosol phase.

[31] The skewness (bottom of middle column of Figure 4) is a dimensionless measure of the asymmetry of the probability distribution. Due to strong updrafts and large-scale areas with slow sinking motions, the vertical wind is positively skewed in

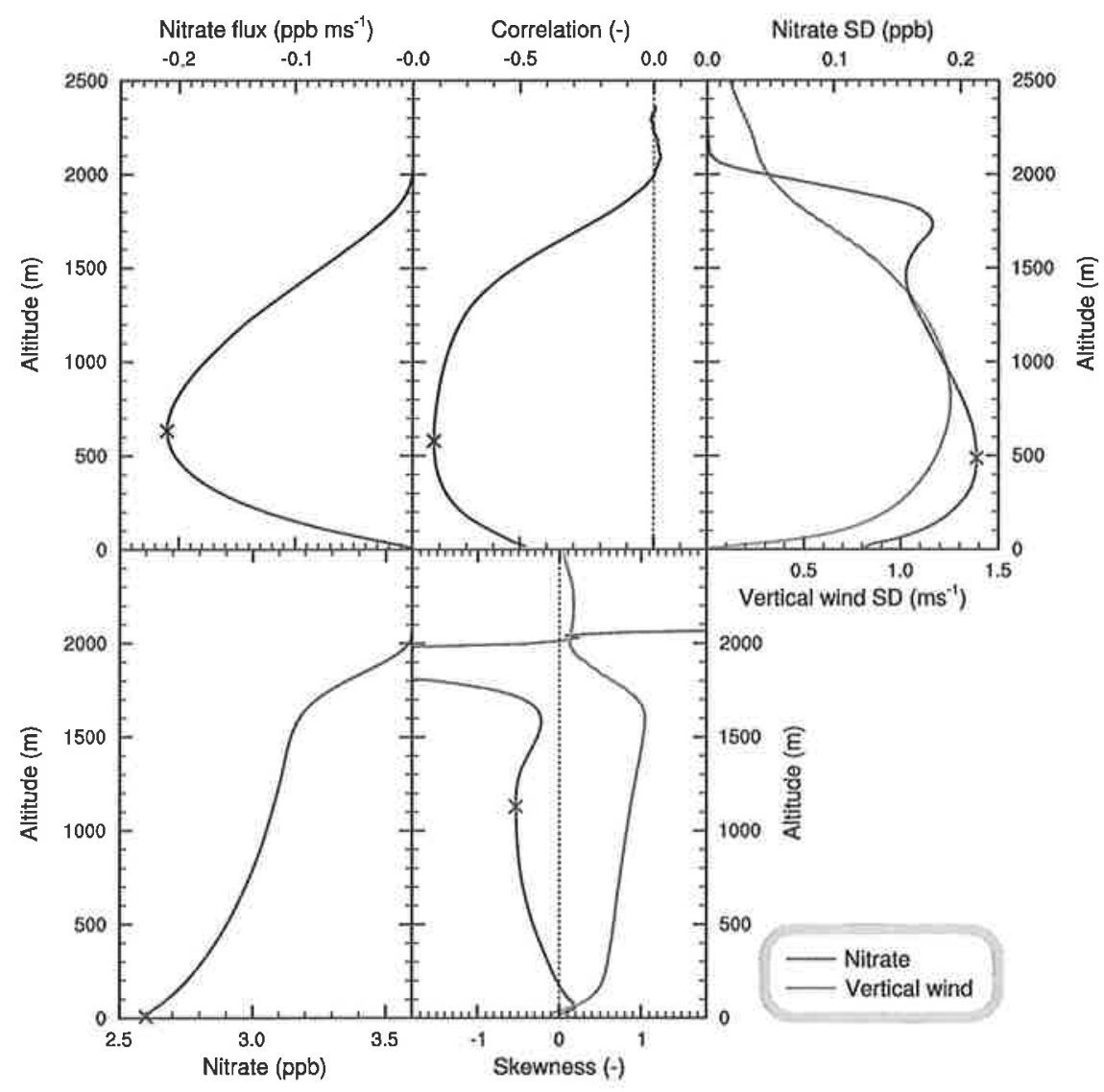

Figure 4. Modeled vertical profiles of the nitrate flux, the correlation coefficient between nitrate and vertical wind fluctuations, the standard deviation of nitrate and vertical wind, the average nitrate mixing ratio and the skewness of nitrate and vertical wind. All profiles are time-averaged over the period from 13:00 to 16:00 UTC. The time scale of partitioning is set to $1800 \mathrm{~s}$. Characteristic points of the profiles are marked. 
a convective boundary layer [Moeng and Rotunno, 1990]. Because the nitrate mixing ratio anticonelates with the vertical wind, a negative skewness is expected for nitrate. This is the case for the majority of the boundary layer, although above $1 \mathrm{~km}$ altitude, the weaker correlation causes the nitrate skewness to be less in magnitude than the vertical velocity skewness (see bottom of middle column of Figure 4). The skewness of nitrate in the free troposphere is undefined as fluctuations are suppressed.

\subsection{Sensitivity to the Partitioning Time Scale}

[32] To assess the sensitivity to the assumed partitioning time scale, the simulation has been repeated with different assumpions for the partitioning time scales (see equation (1)). The profiles as shown in Figure 4 change only little in shape, but vary significantly in magnitude. To compare these profiles for the different partitioning time scales, we summarize each profile with the most extreme value in the boundary layer, disregarding features in the entrainment zone. These points are marked with crosses in Figure 4.

[33] Figure 5 presents how the profiles change with assumed partitioning time scale. The largest flux and standard deviation in nitrate are modeled when the partitioning time scale is assumed to be $450 \mathrm{~s}$ (around half the time scale of an eddy turnover in the convective boundary layer) at

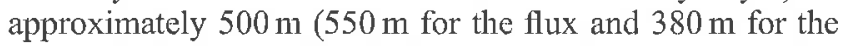
standard deviation). For both short and long partitioning time scales, the flux and standard deviation are suppressed. For short partitioning time scales, the nitrate mixing ratio approaches the equilibrium (bottom of right column in Figure 2). As discussed there, the horizontal standard deviation of this nitrate equilibrium is low $(<0.1 \mathrm{ppb}$ at the surface, decreasing with altitude). Figure 5 (third panel) shows that for short partitioning time scales, the largest standard deviation of the nitrate mixing ratio is indeed located near the surface and reaches a value around $0.1 \mathrm{ppb}$. For long partitioning time scales, the nitrate mixing ratio approaches a well-mixed profile throughout the entire boundary layer, so variability is suppressed. With small horizontal variability, the flux is simall as well. The correlation between vertical wind and nitrate mixing ratio is a large negative number $\left(-0.89\right.$ at $\tau_{p}=450 \mathrm{~s}$ slightly increasing to more moderate values with increasing $\tau_{p}$ ). Because of the low sensitivity of $r_{w C}$ to the partitioning time scale, the nitrate flux and the nitrate standard deviation behave similarly (equation (7)). The nitrate skewness remains rather constant $(-1.2$ to -1.5$)$ until $\tau_{p}$ exceeds 10 min, after which large negative skewness disappears.

\subsection{Probability Density Functions}

[34] The relationship between the nitrate mixing ratio and the vertical wind can be visualized with two-dimensional probability density functions (2D-PDFs, see Figure 6). Such a 2D-PDF is constructed with all data points (nitrate and vertical wind) at one altitude for the entire analysis period. As reference case, representative for the convective boundary layer, we take $z=500 \mathrm{~m}$ and $\tau_{p}=1800 \mathrm{~s}$.

[35] The probability density function generally shows that nitrate and vertical wind are strongly anticorrelated and significantly skewed, with more extreme values with upward wind and low nitrate mixing ratio. At different altitudes, the shapes of the 2D-PDFs are slightly different. At $1300 \mathrm{~m}$ altitude, moderate downdrafts $\left(w \sim-0.5 \mathrm{~ms}^{-1}\right)$ contain more

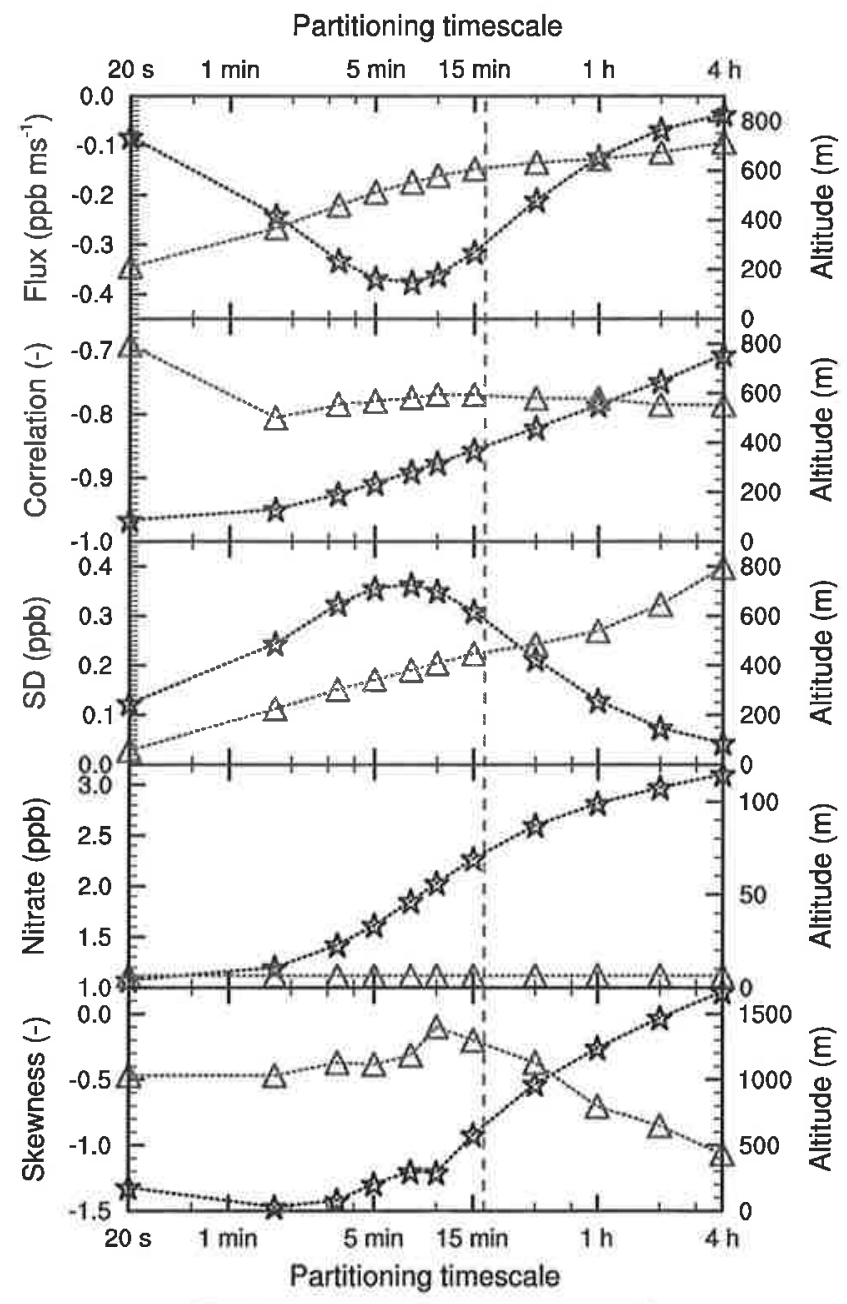

s) Property $\triangle$ Altitude $; \overline{\tau_{t}}$

Figure 5. Sensitivity of the vertical profiles of the nitrate flux, the nitrate standard deviation, the correlation between nitrate and vertical wind fluctuations, the average nitrate mixing ratio, and the nitrate skewness, to the assumed partitioning time scale. Profiles are characterized by the most extreme value in the boundary layer, disregarding features in the entrainment zone. The time scale of turbulence averaged over the analysis period is marked. The displayed altitudes are the altitudes where the extreme values are found.

frequently very high nitrate mixing ratios $(>3.3 \mathrm{ppb})$ than strong downdrafts $\left(w<-1 \mathrm{~ms}^{-1}\right)$. The reason for this feature is that slowly moving air has resided a longer period in the upper boundary layer, where the aerosol phase prevails. At $100 \mathrm{~m}$ altitude, the vertical velocity is much lower (closer to zero) because the eddies close to the surface are smaller. Also, the correlation between nitrate and vertical wind is weaker $\left(r_{n C}=-0.6\right)$, indicating that, because of the less coherent eddies close to the surface, the actual vertical wind is a less good indicator for the history of the air parcel than at higher altitudes. Finally, the 2D-PDF shows sharper and straighter edges at shorter ( $300 \mathrm{~s}$ ) partitioning time scales. In such case, the nitrate mixing ratio becomes more predictable, because only a shorter history of the air parcel is relevant. 

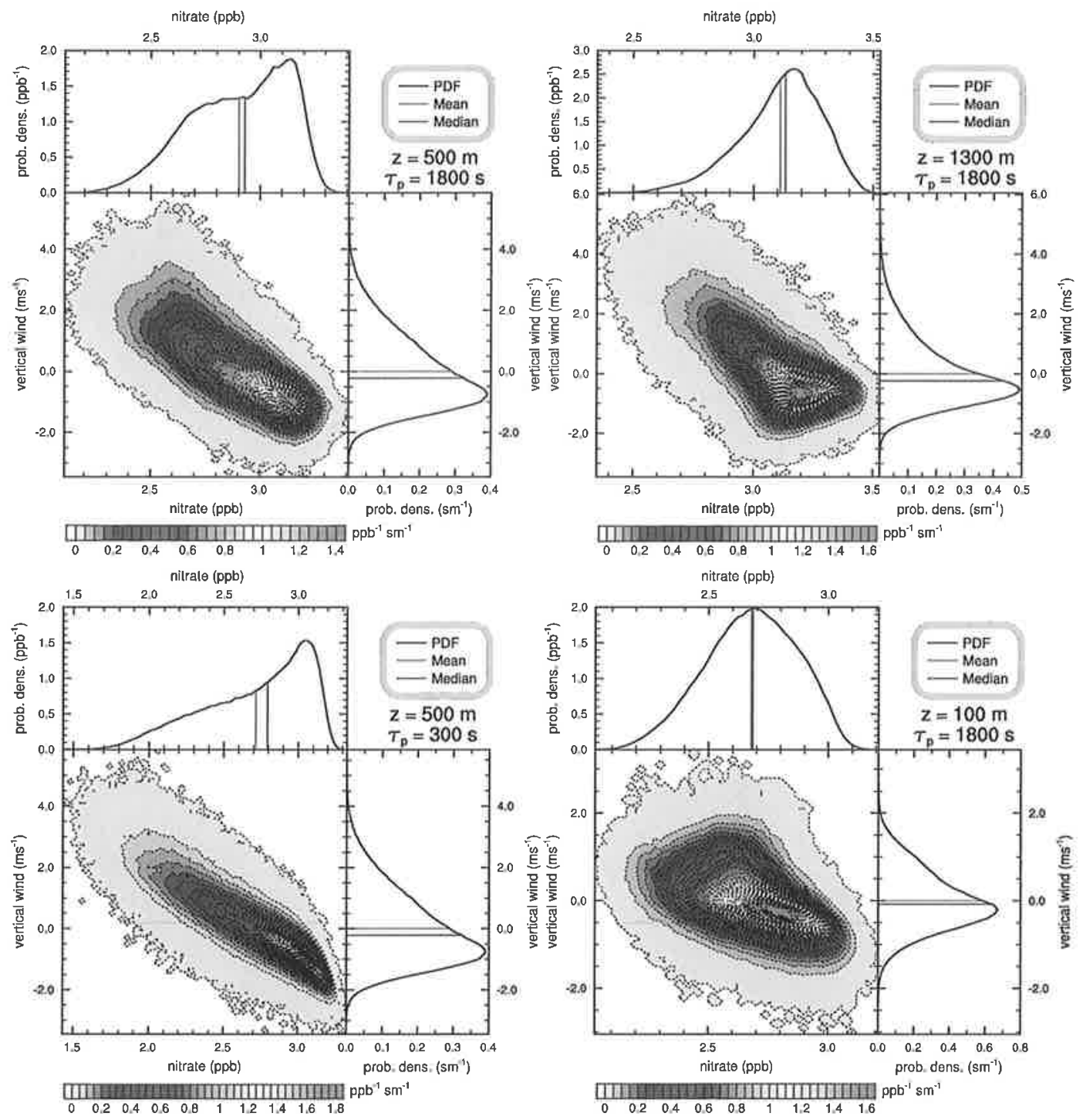

Figure 6. Probability density functions for nitrate mixing ratio and vertical wind at one altitude.

\subsection{Effects of a Colder Boundary Layer on the Partitioning}

[36] To investigate the effect of colder conditions, the simulation $\left(\tau_{p}=1800 \mathrm{~s}\right)$ has been repeated for a colder day, 21 May 2008. During the analysis period on 21 May, the surface temperature is much $\left(5.6^{\circ} \mathrm{C}\right)$ lower and the relative humidity at the surface is slightly $(8.3 \%)$ higher than on 8 May. However, the turbulent properties of the boundary layer were similar to 8 May. Under these colder conditions, a smaller fiaction of nitrate outgasses at the surface, reducing the difference in the nitrate mixing ratio between the surface and higher altitudes by a factor of four to five. Because of this, the nitrate flux and the nitrate standard deviation are reduced by a similar factor. However, the dimensionless properties, correlation and nitrate skewness, are rather insensitive to these conditions.

[37] The probability density function of the colder day (Figure 7) summarizes the sensitivity of the system to the meteorological conditions adequately. The only significant difference is that the nitrate mixing ratios are shifted to higher values and compressed to a smaller range. Consequently, the probability densities in the compressed nitrate domain are scaled up with the same factor.

\section{Discussion}

[38] The gas-aerosol transition of nitrate has a wide range of time scales, depending on the size and the viscosity of the aerosols [Shiraiwa et al., 2011]. This time scale is very difficult to derive from in situ measurements. Our LES shows that statistical information from measurements in the convective boundary layer of the vertical wind and nitrate mixing ratios can potentially help to obtain information about the partitioning time scale. We have also shown under colder conditions, the statistical indicators of the partitioning time scale remain the same, but with much smaller fluctuations in the nitrate mixing ratio.

[39] We expect that the statistics of the nitrate mixing ratio fluctuations are more strongly influenced by large-scale subsidence, a different Bowen ratio or a different initial stratification 


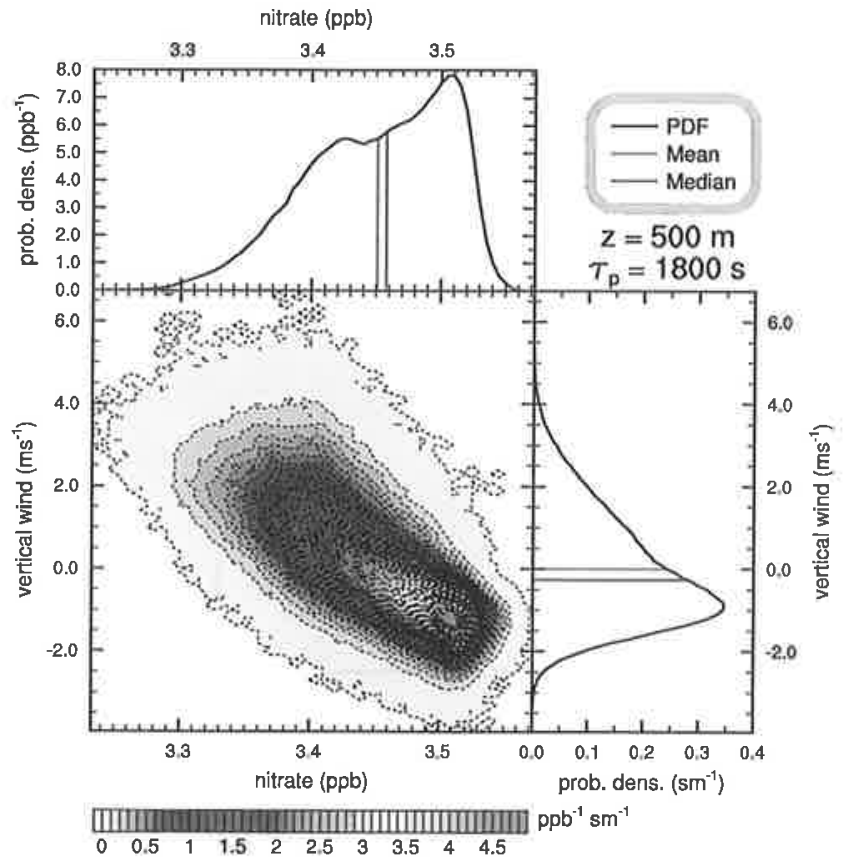

Figure 7. Probability density functions for nitrate mixing ratio and vestical wind at $500 \mathrm{~m}$ altitude for the cold-case simulation. The partitioning time scale is set to $1800 \mathrm{~s}$.

of the free troposphere. In the cold case, the equilibrium nitrate mixing ratio profile became more constant with height (lower $\left.\frac{d C e q}{d z}\right)$, resulting in less pronounced nitrate mixing ratio fluctuations. In addition to turbulence, other chemical factors influence only the profile of $\frac{d C i d}{d z}$. Examples are the concentrations of total nitrate and other species involved (e.g., total ammonium, total sulfate, sodium, and total chloride). For such perturbations, we expect that the nitrate mixing ratio fluctuations can be predicted from the $\frac{d \mathrm{cc}}{d z}$ profile.

[40] Unfortunately, non-modeled surface interactions (e.g., emission and deposition) also influence these statistical properties. Especially deposition of nitric acid is an important process, since not only it is influenced by the phase transition of nitrate, but it also influences the statistical properties of the nitrate mixing ratio by reducing the total nitrate concentration near the surface. Moreover, our simulation assumes horizontally homogeneous conditions, while in reality, heterogeneous land-use and non-uniform emissions also cause variability. Because of these processes, one can expect enhanced nitrate standard deviations and reduced correlations between nitrate and vertical wind in real observations. Heterogeneous concentrations of total nitrate may affect the nitrate skewness as well. As concentrations of pollutants usually show a positive skewness [Lee, 2002], a positive skewness for total nitrate is expected as well, compensating the negative skewness for nitrate that we infer for sholt partitioning time scales as discussed in sections 3.1 and 3.2. Entrainment of freetropospheric air with lower total nitrate mixing ratios can influence the observed nitrate mixing ratios as well. Intrusion of pristine air is expected to enhance the nitrate standard deviation and to reduce the nitrate skewness in the entrainment zone [Mahrt, 1991]. This effect is minimized in the model, because the total nitrate mixing ratio in the free troposphere is set equal to that of the boundary layer.
[41] Experimental determination of the partitioning time scale through sampling of fluctuations of the nitrate mixing ratio and the vertical wind will be better determined under homogeneous conditions. Observations should preferably be performed when the wind is weak and steady. Furthermore, airborne measurements with a low-speed vessel, such as a balloon or a zeppelin, minimize the spatial range of the observations and thereby the influence of heterogeneity. Note that it is important to perform measurements at high altitudes (e.g., $z>300 \mathrm{~m}$ ), since the model results show that the effects are strongest at sufficiently high altitudes (see Figure 4). By measuring additional species besides nitrate, one could indicate to what extent spatial surface heterogeneity plays a role. It is particularly important to sample the nitric acid mixing ratio to obtain the total nitrate mixing ratio as well, so that it can be determined whether changes in nitrate mixing ratios are induced by repartitioning or by changes in total nitrate mixing ratios. More research is required to understand the effects of heterogeneous conditions on the nitrate partitioning.

[42] The aircraft observations on 8 May by Morgan et al. [2010] indicate that the nitrate mixing ratios are enhanced at higher altitudes and that they have a large spatial variability. Sulfate, an aerosol component that is not subject to repartitioning, does not show these features. These findings are in agreement with the model results presented in this paper (see Figure 4). However, the spatial variability of nitrate in the observations is larger than what would be expected from the homogeneous model results. Furthermore, the skewness of the observed nitrate mixing ratios is positive at all altitudes, which cannot be explained with our homogeneous model results. We hypothesize that a significant fraction of the spatial variability of the nitrate mixing ratios is induced by heterogeneous concentrations of total nitrate (see above and Lee [2002]) or by heterogeneities in other driving factors, such as temperature, humidity, total-ammonium concentrations, and large-scale air motions. The aircraft observations have been collected over quite a large area around Cabauw (see Figure 5 of Morgan et al. [2010]), so that significant spatial heterogeneity could indeed be expected. Note that the spatial variability of the sulfate mixing ratio is not a good proxy for the spatial variability of the total nitrate mixing ratio, because sulfate and nitrate have different sources.

[43] On 21 May, when the conditions are colder, the difference between the phase equilibria at the surface and aloft is smaller. This implies that the features caused by repartitioning are smaller than on $8 \mathrm{May}$. The observations show that there is no significant enhancement of nitrate mixing ratios from $500 \mathrm{~m}$ altitude onward (see section 1) and that the spatial variability of the nitrate mixing ratios is much smaller than on 8 May.

[44] Our model simulations predict that local measurements of nitrate mixing ratios in a convective boundary layer show a fluctuating signal. One might be inclined to ascribe the signal to instrument noise. However, as pointed out above, the temporal correlation between nitrate and vertical wind contains valuable information about gas-aerosol partitioning. Unfortunately, experimental confirmation needs fast measurements (more than $1 \mathrm{~Hz}$ ) of the nitrate mixing ratio, which is technically challenging [Crosier et al., 2007]. Such fast measurements are normally only performed for specific flux studies at the surface $[$ Farmer et al., 2011; Fowler et al., 2009; Gordon et al., 2011; Nemitz et al., 2008]. Our simulations further predict that gas-aerosol 
partitioning induces a downward flux of nitrate in the convective boundary layer. This is in agreement with Wolff et al. [2010], who pointed out that this downward flux can lead to overestimations of the dry-deposition velocity of nitrate. Several other studies also measured large apparent deposition fluxes of aerosol nitrate and ammonium with an aerosol mass spectrometer eddy-covariance flux system and by measuring concentration gradients [Fowler et al., 2009; Gordon et al., 2011; Nemitz et al., 2004b; Wolff et al., 2011; Wyers and Duyzer, 1997]. We have confirmed that flux measurements of total nitrate are more suitable for estimating deposition velocities.

\section{Conclusion}

[45] This paper presents a study based on an LES of gasaerosol partitioning of nitrate in a convective boundary layer. We have shown that when gas-aerosol partitioning occurs at a time scale comparable to the convective time scale, a structure of updrafts with reduced nitrate mixing ratios and downdrafts with enhanced nitrate mixing ratios arises. These features may appear in observations as rapid fluctuations in nitrate mixing ratios. Also, apparent deposition fluxes of aerosol nitrate, which have been observed by measurement studies, have been reproduced by our model.

[46] Our model results show that the horizontal variance of the nitrate mixing ratio and the nitrate flux is maximum when $\tau_{p} \approx 1 / 2 \cdot \tau_{t}$ and declines for both short and long partitioning time scales. This variance and flux peak at around one third of the boundary layer height, slightly depending on $\tau_{p}$. For short partitioning time scales, the skewness of the nitrate spatial distribution is predicted to be negative due to the strong negative correlation with the vertical velocity. For longer partitioning time scales, the nitrate skewness increases toward zero. Future observations of these statistical properties of the nitrate mixing ratio may provide information about the partitioning time scale, a quantity that is difficult to measure directly.

[47] At colder conditions, the interaction between turbulence and nitrate repartitioning remains qualitatively similar as long as the turbulent properties of the boundary layer remain similar. However, the magnitudes of the nitrate variability and flux are lower at colder conditions, because the phase equilibria at the surface and in the upper boundary layer differ to a smaller extent than at warmer conditions.

[48] Acknowledgments. We would like to thank the NCF (Foundation of national computer facilities) for providing the ability to run DALES on the supercomputer Huygens (project SH-060-12). This work is supported by the EU FP7 IP PEGASOS (FP7-ENV-2010/265148).

\section{References}

Aan de Butigh, J. M. J., J. S. Henzing, M. Schaap, W. T. Morgan, C. C. van Heerwaarden, E. P. Weijers, H. Coe, and M. C. Krol (2012), Modelling the partitioning of ammonium nitrate in the convective boundary layer, Atmos. Chem. Phys, 12, 3005-3023, doi:10.5194/acp-12-3005-2012.

ten Brink, H. M., C. Kruisz, G. P. A. Kos, and A. Bemer (1997), Composition/ size of the light-scatteting aerosol in the Netherlands, Atmos. Environ., 31 , 3955-3962, doi:10.1016/S1352-2310(97)00232-X

ten Brink, H., R. Otjes, P. Jongeman, and G. Kos (2009), Monitoling of the ratio of nitrate to sulphate in size-segregated submicron aerosol in the Netherlands, Atmos. Res, 92(2), 270-276, doi:10.1016/j.atmosres.2008.12.003.

Brost, R. A., A. C. Delany, and B. J. Huebert (1998), Numerical modeling of concentrations of fluxes of $\mathrm{HNO}_{3}, \mathrm{NH}_{3}$, and $\mathrm{NH}_{4} \mathrm{NO}_{3}$ near the surface, J. Geophys. Res., 93(D6), 7137-7152, doi: 10.1029/JD093iD06p07137.
Buijsman, E., H. F. M. Maas, and W. A. H. Asman (1987), Anthropogenic $\mathrm{NH}_{3}$ emissions in Europe, Atmos. Environ., 21, 1009-1022, doi:10.1016/ 0004-6981(87)90230-7.

Crosier, J., J. D. Allan, H. Coe, K. N. Bower, P. Formenti, and P. I. Williams (2007), Chemical composition of summertime aerosol in the Po Valley (Italy), northern Adriatic and Black Sea, Q. J. Roy. Meteorol. Soc, 133 (S1), 61-75, doi:10.1002/qj.88

Cuijpers, J. W. M. and P. G. Duynkerke (1993), Large eddy simulation of trade wind cumulus clouds, J. Atmos. Sci, 50, 3894-3907, doi:10.1175/ 1520-0469(1993)050<3894:LESOTW $>2.0 . C O ; 2$.

Dlugi, R., et al., (2010), Turbulent exchange and segregation of $\mathrm{HO}_{\mathrm{x}}$ and volatile organic compounds above a deciduous forest, Atmos. Chem. Phys., 10, 6215-6235, doi:10.5194/acp-10-6215-2010.

Dosio, A. (2005), Turbulent dispersion in the atmospheric convective boundary layer, PhD thesis, Wageningen University.

Farmer, D. K., J. R. Kimmel, G. Phillips, K. S. Docherty, D. R. Worsnop, D. Sueper, E. Nenitz, and J. L. Jimenez (2011), Eddy covariance measurements with high-resolution time-of-flight aerosol mass spectrometry: A new approach to chemically resolved aerosol fluxes, Atmos. Chem. Phys., 4, 1275-1289, doi:10.5194/amt-4-1275-201l.

Fisseha, R., J. Dommen, L. Gutzwiller, E. Weingartner, M. Gysel, C. Emmenegger, M. Kalberer, and U. Baltensperger (2006), Seasonal and diunal characteristics of water soluble inorganic compounds in the gas and aerosol phase in the Zurich area, Atmos. Chem. Phys, 6, 1895-1904, doi:10.5194/acp-6-1895-2006.

Fountoukis, C. and A. Nenes (2007), ISORROPIA II: A computationally efficient thermodynamic equilibrium model for $\mathrm{K}^{+}-\mathrm{Ca}^{2+}-\mathrm{Mg}^{2+}-\mathrm{NH}_{4}^{+}$ $\mathrm{Na}^{+}-\mathrm{SO}_{4}^{2-}-\mathrm{NO}_{3}^{-}-\mathrm{Cl}^{-}-\mathrm{H}_{2} \mathrm{O}$ acrosols, Atmos. Chem. Phys., 7, 46394659, doi:10.5194/acp-7-4639-2007.

Fowler, D., et al., (2009), Atmospheric composition change: Ecosystematmosphere interactions, Atmos. Environ., 43, 5193-5267, doi: $10.1016 /$ j.atmosenv.2009.07.068

Gordon, M., R. M. Staebler, J. Liggio, A. Vlasenko, S.-M. Li, and K. Hayden (2011), Aerosol fux measurements above a mixed forest at Borden, Ontario, Atmos. Chem. Phys., 11, 6773-6786, doi: 10.5194/acp-11-6773-2011.

Haywood, J. and O. Boucher (2000), Estimates of the direct and indirect radiative forcings due to tropospheric aerosols: a review, Rev. Geophys., $38,513-543$.

van Heerwaarden, C. C. and J. Vilà-Guerau de Arellano (2008), Relative humidity as an indicator for cloud fomation over heterogeneous land surfaces, J. Atmos. Sci., 65, 3263-3277, doi:10.1175/2008JAS2591.1.

Hess, M., P. Koepke, and I. Schult (1998), Optical properties of aerosols and clouds: The software package OPAC, B. Am. Meteorol. Sac., 79 , 831-844, doi:10.1175/1520-0477(1998)079<0831:OPOAAC $>2.0 . \mathrm{CO} ; 2$

Heus, T., C. C. van Heelwaarden, H. J. J. Jonker, A. P. Siebesma, S. Axelsen, K. van den Dries, O. Geoffioy, A. Moene, D. Pino, S. R. de Roodeo, and J. Vila-Guerau de Arellano (2010), Formulation of the Dutch atmospheric large-eddy simulation (DALES) and overview of its applications, Geosci. Model. Dev., 3, 415-444, doi:10.5194/gnid-3-415-2010.

Huebert, B. J., W. T. Luke, A. C. Delany, and R. A. Brost (1988), Measurements of concentrations and diy surface fluxes of atmospheric nitrates in the presence of ammonia, J. Geophys. Res., 93(D6), 7127-7136, doi:10.1029/JD093iD06p07127.

Intergovemmental Panel on Climate Change, (2007), Solomon, S., D. Qin, M. Manning, Z. Chen, M. Marquis, K. B. Averyt, M. Tignor, and H. L. Miller (Eds.) Climate Cliange 2007: The Physical Science Basis, IPCC Fourth Assessment Report (AR4).

Kaufman, Y. J., D. Tanré, and O. Boucher (2002), A satellite view of aerosols in the climate system, Nature, 419, 215-223.

Kramm, G. and R. Dlugi (1994), Modelling of the vertical fluxes of nitric acid, ammonia and ammonium nitrate, J. Amos. Chem., 18, 319-357.

Krol, M. C., M. J. Molemaker, and J. Vilà-Guerau de Arellano (2000), Effects of turbulence and heterogeneous emissions on photochemically active species in the convective boundary layer, J. Geophys. Res, 105, 6871-6884, doi:10.1029/1999JD900958.

Lee, C. K. (2002), Multifractal characteristics in air pollutant concentration time series, Water Air Soil Pollut, 135, 389-409, doi:10.1023// A:1014768632318.

Mahrt, L. (1991), Boundary-layer moisture regimes, Q. J. Roy. Meteorol. Soc., 177, 151-176, doi:10.1002/qj49711749708.

Meng, Z. and J. H. Seinfeld (1996), Time scales to achieve atmospheric gasaerosol equilibrium for volatile species, Atmos. Environ., 30, 2889-2900, doi: $10.1016 / 1352-2310(95) 00493-9$.

Moeng, C.-H. and R. Rotunno (1990), Vertical-velocity skewness in the buoyancy-driven boundary layer, $J$. Atmos. Sci., 47, 1149-1162, doi: $10.1175 / 1520-0469(1990) 047<1149$ :VVSITB $>2.0 . C O ; 2$.

Morgan, W. T., et al., (2010), Enhancement of the aerosol direct radiative effect by semi-volatile aerosol components: Airborne measurements in North-Western Europe, Atmos. Chem. Phys., 10, 8151-8171, doi:10.5194/ acp-10-8151-2010. 
Monino, Y., Y. Kondo, N. Takegawa, Y. Miyazaki, K. Kita, Y. Komazaki, M. Fukuda, T. Miyakawa, N. Moteki, and D. R. Worsnop (2006) Partitioning of $\mathrm{HNO}_{3}$ and particulate nitrate over Tokyo: Effect of vertical mixing, J. Geophys. Res., 111, D15215, doi:10.1029/2005JD006887.

Moya, M., A. S. Ansari, and S. N. Pandis (2001), Partitioning of nitrate and ammonium between the gas and particulate phases during the 1997 IMADA-AVER study in Mexico City, Atmos. Environ., 35(10), 1791-1804, doi:10.1016/S1352-2310(00)00292-2.

Neftel, A., A. Blatter, R. Hesterberg, and T. Staffelbach (1996), Measurements of concentration gradients of $\mathrm{HNO}_{2}$ and $\mathrm{HNO}_{3}$ over a semi-natural ecosystem, Atmos. Environ., 30(17), 3017-3025, doi:10.1016/1352-2310 (96)00011-8.

Nemitz, E. and M. A. Sutton (2004), Gas-particle interactions above a Dutch heathland: III. Modelling the influence of the $\mathrm{NH}_{3}-\mathrm{HNO}_{3}-\mathrm{NH}_{4}$ $\mathrm{NO}_{3}$ equilibrium on size-segregated particle fluxes, Atmos. Chem. Phys., 4, 1025-1045, doi: 10.5194/acp-4-1025-2004.

Nemitz, E., M. A. Sutton, G. P. Wyers, and P. A. C. Jongejan (2004a), Gasparticle interactions above a Dutch heathland: I. Surface exchange fluxes of $\mathrm{NH}_{3}, \mathrm{SO}_{2}, \mathrm{HNO}_{3}$ and $\mathrm{HCl}$, Atmos. Chem. Phys., 4, 989-1005, doi: 10.5194/acp-4-989-2004

Nemitz, E., M. A. Sutton, G. P. Wyers, R. P. Otjes, M. G. Mennen, E. M. van Putten, and M. W. Gallagher (2004b), Gas-particle interactions above a Dutch heathland: II. Concentrations and surface exchange fluxes of atmospheric particles, Atmos. Chem. Phys., 4, 1007-1024, doi:10.5194/acp-4-1007-2004. Nemitz, E., J. L. Jimenez, J. A. Huffman, I. M. Ulbrich, M. R. Canagaratu, D. R. Worsnop, and A. B. Guenther (2008), An eddy-covariance system for the measurement of surface/atmosphere exchange fluxes of submicron aerosol chemical species-first application above an urban area, Aerosol. Sci. Technol., 8, doi:10.1080/02786820802227352.

Nenes, A., S. N. Pandis, and C. Pilinis (1998), ISORROPIA: A new themodynamic equitibrium model for multiphase multicomponent inorganic aerosols, Aquat. Geochem., 4, 123-152, doi:10.1023/A:1009604003981.

Nieuwstadt, F. T. M. and R. A. Brost (1986), The decay of convective turbulence, J. Atmos. Sci., 43, 532-545, doi:10.1175/1520-0469(1986) $043<0532 \% 3 \mathrm{ATDOCT}>2.0 . \mathrm{CO} ; 2$.

van Oss, R., J. Duyzer, and P. Wyers (1998), The influence of gas-to-particle conversion on measurements of ammonia exchange over forest, Atmos. Environ., 32(3), 465 471, doi: 10.1016/S1352-2310(97)00280-X. Ouwersloot, H. G., J. Vilà-Guerau de Arellano, C. C. van Heerwaarden, L. N. Ganzeveld, M. C. Krol, and J. Lelieveld (2011), On the segregation of chemjcal species in a clear boundary layer over heterogeneous land surfaces, Atmos. Chem. Phys., 11, 10681-10704, doi:10.5194/acp-11-10681-2011.

Pugh, T. A. M., A. R. MacKenzie, B. Langford, E. Nemitz, P. K. Misztal, and C. N. Hewitt (2011), The influence of small-scale variations in isoprene concentrations on atmospheric chemistry over a tropical rainforest, Atmos. Chem. Phys., II, 4142 4134, doi:10.5194/acp-11-4121-2011.

Rosenfeld, D., U. Lohmann, G. B. Raga, C. D. O'Dowd, M. Kulmala, S. Fuzzi, A. Reissell, and M. O. Andreae (2008) Flood or drought: How do aerosols affect precipitation?, Science, 321, 1309-1313, doi:10.1126/ science. 1160606

Russchemberg, H. W. J., et al., (2005), Ground-based atmospheric temote sensing in the Netherlands; European outlook, IEICE Transactions on Communications E88-B(6), 2252-2258: doi:10.1093/ietcom/e88-b.6.2252.

Ryder, J. (2010), Emission, deposition and chemical conversion of atmospheric trace substances in and above vegetation canopies, $P h D$ Thesis, University of Manchester, Manchester, $241 \mathrm{pp}$.

Schaap, M., R. P. Otjes, and E. P. Weijers (2011), Illustrating the benefit of using hourly monitoring data on secondary inorganic aerosol and its precursors for model evaluation, Atmos. Chen. Phys., 11, 11041-11053, doi:10.5194/acp-11-11041-2011.

Schumann, U (1989), Large-eddy simulation of turbulent diffusion with chemical reactions in the convective boundary layer, Atmos. Environ. 23, 1713-1727, doi:10.1016/0004-6981(89)90056-5.

Shiraiwa, M., M. Ammam, T. Koop, and U. Poschl (2011), Gas uptake and chemical aging of semi-solid organic aerosol particles, $P$. Natl. Acad. Sci. $U S A, 108(27), 11003-11008$, doi:10.1073/pnas. 1103045108.

Stelson, A. W. and J. H. Seinfeld (1982), Relative humidity and temperature dependence of the ammonium nitrate dissociation constant, Atmos. Environ. 16,983-992, doi:10.1016/0004-6981(82)90184-6.
Stull, R. B. (1988), An Introduction to Boundary Layer Meteorology, Kluwer Academic Publishers.

Sykes, R. L., D. S. Henn, S. F. Parker, and W. S. Lewellen (1992), Largeeddy simulation of a turbulent reacting plume, Atnos. Environ., $26 \mathrm{~A}$, 2565-2574, doi:10.1016/0960-1686(92)90109-X.

Takahama, S. A. E. Wittig D. V. Vayenas, C. I. Davidson, and S. M Pandis (2004), Modeling the diumal variation of nitrate during the Pittsburgh Ait Quality Study, J. Geophys. Res., 109, D16S06, doi:10.1029/2003JD004149.

Tennekes, H. and A. G. M. Driedonks (1981), Basic entrainment equations for the atmospheric boundary layer, Bound. Lay. Meteorol., 20, 515-531, doi: 10.1007/BF00122299.

Thomas, R. M., I. Trebs, R. Otjes, P. A. C. Jongejan, H. ten Brink, G. Phillips, M. Kortner, F. X. Meixner, and E. Nemitz (2009), All automated analyzer to measure surface-atmosphere exchange fluxes of water soluble inorganic aerosol compounds and reactive trace gases, Environ. Sci. Technol., 43(5), 1412-1418, doi:10.1021/es8019403.

Vestreng, V., G. Myhre, H. Fagerli, S. Reis, and L. Tarrasón (2007), Twentyfive years of continuous sulphur dioxide emission reduction in Europe, Atmos. Chem. Phys, 7, 3663-3681, doi:10.5194/acp-7-3663-2007.

Vestreng, V., L. Ntziachristos, A. Semb, S. Reis, I. S. A. Isaksen, and L. Tarrasón (2009), Evolution of $\mathrm{NO}_{\mathrm{x}}$ emissions in Europe with focus on road transport control measures, Atmos. Chem. Phys., 9, 1503-1520, doi:10.5194/acp-9-1503-2009.

Vilà-Guerau de Arellano, J., P. G. Duynkerke, and P. J. H. Builtjes (1993a) The divergence of the turbulent diffusion flux in the surface layer due to chemical reactions: The $\mathrm{NO}-\mathrm{O}_{3}-\mathrm{NO}_{2}$ system, Tellus, 45B, 23-33, doi: $10.1034 / j .1600-0889.1993 .00002 . x$

Vilà-Guerau de Arellano, J., P. G. Duynkerke, P. J. Jonker, and P. J. H. Builtjes (1993b), An observational study on the effects of time and space averaging in photochemical models, Atmos. Environ, 27A, 353-362, doi: $10.1016 / 0960-1686(93) 90109-\mathrm{C}$

Vilà-Guerau de Arellano, J., S.-W. Kim, M. C. Barth, and E. G. Patton (2005), Transport and chemical transformations influences by shallow cumulus over land, Atmos. Chem. Phys., 5, 3219-3231, doi:10.5194/ acp-5-3219-2005.

Weijers, E. P., M. Schaap, L. Nguyen, J. Matthijsen, H. A. C. Denier van der Gon, H. M. ten Brink, and R. Hoogerbrugge (2011), Authropogenic and natural constituents in particulate matter in the Netherlands, Atmos. Chem. Phys., 11, 2281-2294, doi:10.5194/acp-11-2281-2011.

Wexler, A. S. and J. H. Seiufeld (1992), Analysis of aerosol ammonium nitrate departures from equilibrium during SCAQS, Atmos. Envirom. 26A, 579-591, doi:10.1016/0960-1686(92)90171-G.

Wolff, V., I. Trebs, T. Foken, and F. V. Meixner (2010), Exchange of reactive nitrogen compounds: Concentrations and fluxes of total ammonium and total nitrate above a spruce canopy, Biogeosciences, 7, 1729--1744, doi: 10.5194/bg-7-1729-2010.

Wolff, V., F. X. Meixner, and I. Trebs (2011), Mixing ratios and exchange processes of ammonia-nitric acid-ammonium nitrate triad above a spruce forest canopy. In: H. Lacoste-Francid (Ed.), Earth Observations for LandAtmosphere Interactions Science, Frascati, Italy. European Space Agency, ESTEC, Noordwijk, The Netherlands.

Wyers, G. P. and J. H. Duyzer (1997), Micrometeorological measurement of the dry deposition flux of sulphate and nitrate aerosols to coniferous forest, Atmos, Environ., 3I(3), 333-343, doi:10.1016/S1352-2310(96)00188-4.

Yu, S., R. Dennis, S. Roselle, A. Nenes, J. Walker, B. Eder, K. Schere, J. Swall, and W. Robarge (2005), An assessment of the ability of threedimensional air quality models witl cunent thermodynamic equilibrium models to predict aerosol $\mathrm{NO}_{3}^{-}, J$. Geophys. Res., 10, D07S13, 1-22, doi: $10.1029 / 2004$ JD004718

Zhang, J., W. L. Charmeides, R. Weber, G. Cass, D. Orsini, E. Edgetton, P. Jongejan, and J. Slanina (2003), An evaluation of the themodynanic equilibrium assumption for fine particulate composition: Nitrate and anmonium during the 1999 Atlanta Supersite experiment, J. Geophys. Res., I08(7), doi:10.1029/2001JD001592.

Zhange, Y., H. M. ten Brink, J. Slanina, and G. P. Wyers (1995), The influence of ammonium nitrate equilibrium on the measurement of exchange fluxes of ammonia and nitric acid. In Acid Rain Research: Do We Have Enough Answers?, edited by G. J. Heij and J. W. Erisman, Elsevier Science B. V., 103-112. 